\title{
Novel echocardiographic markers of elevated left ventricular filling pressure during diastolic stress testing
}

\author{
Jan Verwerft, MDa,b; Frederik H. Verbrugge, MD PhD ${ }^{\mathrm{b}, \mathrm{c}, \mathrm{d}}$, Guido Claessen, MD PhD ${ }^{\mathrm{e}, \mathrm{f}}$; \\ Lieven Herbots, MD PhDa; Paul Dendale, MD PhDa,b, Andreas B. Gevaert, MD PhD,g
}

a Heart Centre Hasselt, Jessa Hospital, Hasselt, Belgium

b Biomedical Research Institute, Faculty of Medicine and Life Sciences, Hasselt University, Diepenbeek/Hasselt, Belgium

c Department of Cardiovascular Diseases, Mayo Clinic, Rochester, MN, United States

d Centre for Cardiovascular Diseases, University Hospital Brussels, Brussels, Belgium

e Department of Cardiovascular Sciences, KU Leuven, Leuven, Belgium

f Division of Cardiology, University Hospitals Leuven, Leuven, Belgium

g Research Group Cardiovascular Diseases, Department GENCOR, University of Antwerp, Antwerp, Belgium

Corresponding author: Andreas B. Gevaert, Research Group Cardiovascular Diseases, Department GENCOR, University of Antwerp, Universiteitsplein 1, 2610 Antwerp, Belgium. Tel: +32 3821 3973, Fax: +32 38213974 , andreas.gevaert@uantwerpen.be

Word count: Abstract 248; Manuscript $3301+$ References 883 + Figure legends 573 + Tables $691=$ 5448 
medRxiv preprint doi: https://doi.org/10.1101/2020.12.16.20248175; this version posted December 18, 2020. The copyright holder for this

\section{Abstract}

\section{Aims}

Diastolic stress testing (DST) is recommended to confirm heart failure with preserved ejection fraction (HFpEF) in patients with exertional dyspnea, but algorithms lack sensitivity. We aimed to identify additional echocardiographic markers of elevated pulmonary arterial wedge pressure during exercise (exPAWP) in patients referred for DST.

\section{Methods and Results}

We analyzed 22 patients referred for exercise right heart catheterization with simultaneous echocardiography. We identified candidate parameters in patients with exPAWP $\geq 25 \mathrm{mmHg}$. Elevated exPAWP was present in 14 patients, and was best identified by peak septal systolic annular velocity on color Doppler (exS', area under the receiver operating characteristic curve (AUC) $0.97,95 \%$ confidence interval 0.92-1.0) and mean pulmonary artery pressure/cardiac output slope (mPAP/CO, AUC 0.88 [0.72-1.0]). We propose a three-step decision tree to identify patients with elevated exPAWP. Applying this decision tree to 376 patients in an independent noninvasive DST cohort showed that patients labeled as 'high probability of HFpEF' had reduced peak oxygen uptake $(12.8(10.5-15.9) \mathrm{mL} / \mathrm{kg} / \mathrm{min}, \mathrm{p}<.001$ vs intermediate/low probability), high H2FPEF score (55 (44-75)\%, p<.007 vs intermediate/low probability), and typical clinical characteristics. The amount of inconclusive DST decreased from 80\% using current recommendations, to $29 \%$ using the decision tree.

\section{Conclusion}

In DST for suspected HFpEF, exS' was the most accurate echocardiographic parameter to identify elevated PAWP. We propose a decision tree including exS' and mPAP/CO for interpretation of DST. Application of this decision tree revealed typical HFpEF characteristics in patients labeled as high probability of HFpEF, and substantially reduced the amount of inconclusive results. 
medRxiv preprint doi: https://doi.org/10.1101/2020.12.16.20248175; this version posted December 18, 2020. The copyright holder for this

\section{Introduction}

2 Half of heart failure (HF) patients have a preserved ejection fraction (HFpEF) ${ }^{1}$. Compared to HF

3 with reduced ejection fraction, the diagnosis of $\mathrm{HFpEF}$ is often more challenging, especially when

4 patients are not decompensated ${ }^{2}$. Guidelines recommend using the combination of patient

5 characteristics, natriuretic peptide levels, and echocardiography at rest to make a diagnosis of

6 HFpEF 3,4. However, in patients without gross volume overload who complain from chronic

7 dyspnea, a diagnosis of HFpEF can be easily missed at rest, as many patients only develop

8 symptoms and disproportionate elevation of cardiac filling pressures during exercise 5 .

9

Invasive hemodynamic exercise testing is considered the gold standard to rule in or rule out HFpEF based on a pulmonary arterial wedge pressure (PAWP) $\geq 25 \mathrm{mmHg}$ or $<25 \mathrm{mmHg}$ during symptom-limited supine exercise (exPAWP) ${ }^{6}$. Yet, this strategy is not broadly applied due to logistic restraints and limited expertise. A positive diastolic stress test (DST) in patients with an intermediate to high pretest probability may offer a valuable alternative to confirm the diagnosis of HFpEF, with this approach supported by a recent consensus statement of the Heart Failure Association of the European Society of Cardiology 7. DST refers to the use of echocardiography to detect impaired left ventricular (LV) diastolic functional reserve and disproportionally increased filling pressures during exercise that commonly result in pulmonary hypertension ${ }^{8}$. Accordingly, elevated early mitral inflow velocity over early diastolic annular velocity $(E / e)$ and tricuspid regurgitation (TR) velocity during exercise (exE/e, exTR) are used to support a diagnosis of $\mathrm{HFpEF}^{9,10}$. Although the positive predictive value of the DST is acceptable at $85^{-93} \%$, its negative predictive value is poor $\left(55^{-77 \%}\right)^{11}$.

In this study, the aim was to identify additional echocardiographic markers of elevated PAWP $\geq 25 \mathrm{mmHg}$ assessed by gold-standard invasive hemodynamic exercise testing performed because of unexplained exertional dyspnea. Subsequently, we aimed to apply these echocardiographic parameters in an independent cohort referred for non-invasive DST. 
medRxiv preprint doi: https://doi.org/10.1101/2020.12.16.20248175; this version posted December 18, 2020. The copyright holder for this

\section{Methods}

\section{Study population}

3 We performed a retrospective analysis of patients referred to Jessa Hospital (Hasselt, Belgium)

4 because of exertional dyspnea not sufficiently explained by resting examinations. We screened

5 patients referred from April 2017 to May 2020. Inclusion criteria were: left ventricular ejection

6 fraction (LVEF) $\geq 50 \%$, no more than mild valvular stenosis at rest, no more than moderate left-

7 sided valvular insufficiency at rest, and no indication that pulmonary disease was the sole cause of

8 exertional dyspnea (as assessed by the referring physician). Non-invasive DST was performed in all

9 consecutive patients (DST cohort). If non-invasive DST was inconclusive, patients were offered invasive hemodynamic exercise testing with simultaneous echocardiography and gas exchange measurement (exRHC cohort). We used the exRHC cohort for derivation of the echocardiographic variables associated with elevated PAWP. We applied these novel variables to the DST cohort. Patients included in the exRHC cohort were excluded from validation analyses in the DST cohort. This study complies with the Declaration of Helsinki and was approved by the Ethical Committee of the Jessa Hospital. All patients provided informed consent.

\section{Study protocol}

All patients underwent a cardiopulmonary exercise test (CPET) with respiratory gas analysis (CS200, Schiller). Exercise was performed on a semi-supine bicycle ergometer (ErgoLine) with a continuous ramp protocol aimed for a total exercise duration of 10-12 min. In the DST cohort, 2 stage holds were performed at the aerobic threshold and at peak exercise for image acquirement. In the exRHC cohort, a pulmonary artery catheter (Edwards Lifesciences) was placed under fluoroscopic guidance at the catheterization lab before start of the CPET. In addition, the right radial artery was cannulated with a $5 \mathrm{~F}$ arterial catheter. The fluid filled catheters were then connected to a pressure transducer unit (PowerLab, ADInstruments) with zeroing at the mid axillary level. Every 3 minutes during exercise and at peak exercise, arterial and mixed venous blood gas samples were obtained and PAWP was measured. Other hemodynamic measurements were registered continuously. Echocardiography data was simultaneously collected at aerobic threshold and peak exercise. Hemodynamic tracings were stored in LabChart v8.1 
medRxiv preprint doi: https://doi.org/10.1101/2020.12.16.20248175; this version posted December 18, 2020. The copyright holder for this

1 (ADInstruments) for offline analysis by an experienced cardiologist blinded to echocardiographic measurements (J.V.). All pressure measurements were performed at end-expiration by averaging at least 3 cardiac cycles. Cardiac output (CO) was calculated using the Fick method.

\section{CPET measurements}

5 Ventilation (VE), oxygen uptake $\left(\mathrm{VO}_{2}\right)$ and carbon dioxide production $\left(\mathrm{VCO}_{2}\right)$ were continuously

6 measured through a face mask during exercise. The aerobic threshold was defined as a sustained

7 rise in $\mathrm{O}_{2}$ ventilatory equivalent, the anaerobic threshold was defined as a sustained rise in $\mathrm{CO}_{2}$

8 ventilatory equivalent. Peak $\mathrm{VO}_{2}$ was defined as the highest 10-second average of $\mathrm{VO}_{2}$ during 9 exercise ${ }^{12}$.

\section{Echocardiographic measurements}

Measurements were performed offline using EchoPAC software (GE Healthcare) according to current guidelines ${ }^{10,13}$. Examinations were performed with Vivid E9 (GE Healthcare). Peak mitral systolic annular velocity $(S)$ was assessed on color tissue Doppler imaging (TDI) at the level of the septal mitral annulus (Supplemental Figure 1, Supplemental File 1). Medial $e$ ' was measured at the septal mitral valve annulus using pulse wave TDI. Systolic pulmonary artery pressure (sPAP) was estimated from TR velocity without adding right atrial pressure. Colloid enhancement of the tricuspid insufficiency signal was systematically employed as previously described ${ }^{14}$. Mean PAP (mPAP) was calculated by the Chemla formula as $\mathrm{SPAP}^{*} 0.61+2$. Stroke volume (SV) and CO were calculated using the left ventricular outflow tract method.

In 22 patients, measurements were repeated twice in a blinded fashion by 3 observers, to assess intra-observer variability.

\section{Definitions and thresholds}

Elevated cardiac filling pressures were primarily defined as a peak exercise PAWP $\geq 25 \mathrm{mmHg}$ on invasive hemodynamic assessment, and alternatively as PAWP/CO slope $\geq 2.0 \mathrm{mmHg} / \mathrm{L}^{5,15}$. Exercise pulmonary hypertension was defined as $\mathrm{mPAP} / \mathrm{CO}$ slope $\geq 3.0 \mathrm{mmHg} / \mathrm{L}$ by invasive hemodynamic assessment, and $\geq 3.2 \mathrm{mmHg} / \mathrm{L}$ by echocardiography, as previous studies reported higher values on echocardiography ${ }^{14}$. 
medRxiv preprint doi: https://doi.org/10.1101/2020.12.16.20248175; this version posted December 18, 2020. The copyright holder for this

1 Rule-in and rule-out of HFpEF on non-invasive DST was defined according to the most recent

2 American Society of Echocardiography (ASE) and European Association of Cardiovascular Imaging

3 (EACVI) recommendations ${ }^{9,10}$. HFpEF was diagnosed when septal $e x E / e^{\prime} \geq 15$, exTR $>2.8 \mathrm{~m} / \mathrm{s}$ and

4 baseline $e^{\prime}<7 \mathrm{~cm} / \mathrm{s}$, HFpEF was ruled out when septal $e x E / e^{\prime}<10$ and exTR $<2.8 \mathrm{~m} / \mathrm{s}^{9,10}$.

5 To evaluate the performance of the novel echocardiographic markers of elevated exPAWP, the

6 probability of HFpEF according to the novel marker was compared to surrogate HFpEF indicators:

7 peak $\mathrm{VO}_{2}$ and logistic $\mathrm{H} 2 \mathrm{FPEF}$ score. The latter calculates the probability of HFpEF through

8 clinical and echocardiographic parameters, and has been developed using invasive exRHC

9 measurements ${ }^{16}$.

\section{Sample size calculation}

Using f test power calculation for repeated measures (GPower v3.1.9), we estimated that a sample of 16 patients would provide $90 \%$ power to detect a difference in echocardiographic parameters between elevated and normal PAWP. Effect size was based on the difference in $e x E / e$ ' in the study by Obokata et al ${ }^{11}$.

\section{Statistical analysis}

Continuous variables were expressed as mean \pm standard deviation or median (interquartile range) in case of a skewed distribution. Categorical variables were expressed as percentages. Baseline comparisons were performed using Mann-Whitney-U test, Pearson's Chi-squared test or Fisher's Exact test where appropriate. Comparisons between 3 groups were performed using Kruskal-Wallis test with Dunn test for between-group comparisons (continuous variables), and Pearson's Chisquared test with pairwise nominal independence test (categorical variables). Interobserver variability was calculated using a two-way agreement intra-class correlation model and using Bland-Altman plots.

DST parameters were compared between patients with elevated vs. normal exPAWP using MannWhitney-U test (single measurement during DST, for example mPAP/CO slope) or linear mixed models (repeated measurement during DST, for example $E / e$ ). Linear mixed models were constructed using patient number as random factor, and exercise, elevated exPAWP, and their 
medRxiv preprint doi: https://doi.org/10.1101/2020.12.16.20248175; this version posted December 18, 2020. The copyright holder for this preprint (which was not certified by peer review) is the author/funder, who has granted medRxiv a license to display the preprint in perpetuity. All rights reserved. No reuse allowed without permission.

1 interaction as fixed factors. For each DST parameter with potential to identify elevated exPAWP, a

2 receiver operating characteristic curve was determined, and area under the curve (AUC) was

3 calculated with the trapezoidal rule. 95\% confidence intervals (CI) were calculated using stratified

4 bootstrap replicates. AUC were compared using Delong’s test.

5 Holm method was used as correction for multiple comparisons. A two-sided p-value $<0.05$ was

6 considered significant. All data was analyzed using R v3.6.3 (R Foundation for Statistical

7 Computing) with packages FSA, irr, multcomp, nlme, pROC, plotROC, rcompanion, and tidyverse. 
medRxiv preprint doi: https://doi.org/10.1101/2020.12.16.20248175; this version posted December 18, 2020. The copyright holder for this

\section{Results}

\section{Population}

A total of 398 patients met inclusion criteria, of which 22 patients underwent exRHC, and 376 patients underwent only non-invasive DST. Compared to the exRHC cohort, patients in the DST cohort had a lower prevalence of coronary artery disease, but otherwise similar baseline characteristics (Table 1).

\section{Derivation of peak exercise $\mathbf{S}^{\prime}$ as surrogate for elevated cardiac filling pressures}

In the exRHC cohort, PAWP $\geq 25 \mathrm{mmHg}$ during exercise was recorded in 14 patients, while 8 patients had normal exPAWP (Supplemental Figure 2). Comparison of baseline characteristics revealed older age, lower heart rate, more beta blocker use, and worse renal function in patients with elevated exPAWP (all p<0.05, Supplemental Table 1).

Among echocardiographic parameters, peak exercise septal systolic velocity on color Doppler $\left(e x S^{\prime}\right)$, exE/e', peak sPAP, mPAP/CO slope, peak cardiac index, and rest LV mass index were associated with elevated exPAWP (Figure 1, Supplemental Table 2). Invasive and CPET parameters that were associated with exPAWP $\geq 25 \mathrm{mmHg}$ are displayed in Supplemental Table 2.

$E x S$ ' was the best echocardiographic parameter associated with elevated exPAWP, with an AUC of 0.97 (CI 0.92-1.0), compared to 0.88 (CI 0.72-1.0) for mPAP/CO slope, o.79 (CI 0.58-0.99) for peak cardiac index, 0.76 (CI 0.55-0.96) for $e x E / e$, and 0.76 (CI 0.54-0.97) for peak sPAP (Figure 2, Supplemental Figure 3). $E x S^{\prime}$ had a significantly higher AUC compared to exE/e' (p=0.039) and peak sPAP ( $\mathrm{p}=0.035)$, but not to $\mathrm{mPAP} / \mathrm{CO}$ slope $(\mathrm{p}=0.239)$ or peak cardiac index $(\mathrm{p}=0.099)$.

A threshold of $\operatorname{exS}^{\prime}<9.5 \mathrm{~cm} / \mathrm{s}$ had a specificity of $88 \%$ and sensitivity of $100 \%$ for detecting exPAWP $\geq 25 \mathrm{mmHg}$. $E x E / e^{\prime} \geq 15$ had a specificity of $100 \%$ and sensitivity of $50 \%$; mPAP/CO slope $\geq 3.2 \mathrm{mmHg} / \mathrm{L}$ had a specificity of $63 \%$ and sensitivity of $85 \%$.

As a sensitivity analysis, elevated cardiac filling pressures were alternatively defined as PAWP/CO slope $>2.0 \mathrm{mmHg} / \mathrm{L}$. AUC were comparable to the standard definition for exS' (0.94, CI 0.84-1.0), exE/e' (0.85, CI 0.68-1.0), peak sPAP (0.72, CI 0.46-0.98), and mPAP/CO slope (0.72, CI 0.460.97), but lower for peak cardiac index (0.44, CI 0.17-0.70). 
medRxiv preprint doi: https://doi.org/10.1101/2020.12.16.20248175; this version posted December 18, 2020. The copyright holder for this

\section{Decision tree for determining probability of HFpEF in inconclusive DST}

2 In the exRHC cohort, 6/22 patients had a positive DST according to current recommendations

$3\left(e x E / e^{\prime} \geq 15, \text { exTR }>2.8 \mathrm{~m} / \mathrm{s} \text { and baseline } e^{\prime}<7 \mathrm{~cm} / \mathrm{s}\right)^{9,10}$. All these patients indeed had exPAWP

$4 \geq 25 \mathrm{mmHg}$. In one patient, HFpEF could be excluded according to DST recommendations, and

5 this patient indeed had normal exPAWP. Thus, 8 patients remained with elevated exPAWP and

6 inconclusive DSE. However, all 14 patients with elevated exPAWP had $e x S^{\prime}<9.5 \mathrm{~cm} / \mathrm{s}$. A decision

7 tree consisting of guideline recommendations in a first step and low exS' in a second step (Figure

8 3A), would successfully identify all patients with elevated exPAWP, at the cost of 1 false positive

9 patient (exPAWP $=23 \mathrm{mmHg})$.

10

Most patients with clinically relevant HFpEF exhibit pulmonary hypertension during exercise ${ }^{5,17}$. Indeed all patients with exS'<9.5 and PAWP $\geq 25 \mathrm{mmHg}$ had $\mathrm{mPAP} / \mathrm{CO}$ slope $\geq 3.2 \mathrm{mmHg} / \mathrm{L}$.

Moreover, mPAP/CO slope was the second best parameter in the AUC analysis. Thus, we suggest an algorithm based on a first step assessing exE/e', adding exS' in a second step, and $\mathrm{mPAP} / \mathrm{CO}$ slope in a third step (Figure 3A-B).

\section{Applying the decision tree in the DST cohort}

In the DST cohort, using ASE/EACVI recommendations a diagnosis of HFpEF was made in 71 out of 376 patients (19\%). HFpEF was excluded on DST in 3 patients (1\%). A total of 302 patients (80\%) with inconclusive results remained.

Figure $3 \mathrm{~B}$ shows the application of the proposed decision tree in the DST cohort. Of the 302 patients with inconclusive DST, 184 patients (61\%) had abnormal exS'. Of the 3 patients in which HFpEF was considered unlikely based on guideline recommendations, none had abnormal exS'. Most of the 71 patients in which HFpEF was diagnosed based on ASE/EACVI recommendations (68 patients, 96\%) had abnormal exS'.

Applying the proposed decision tree reduced the number of inconclusive tests from 302 (80\%) to 110 (29\%). A total of 192 patients (64\% of inconclusive tests) could be reclassified as 'high probability of HFpEF' or 'low probability of HFpEF'. Patients in the 'high probability' group had a worse exercise capacity compared to patients with intermediate or low probability: lower peak $\mathrm{VO}_{2}$ 
medRxiv preprint doi: https://doi.org/10.1101/2020.12.16.20248175; this version posted December 18, 2020. The copyright holder for this

1 (Figure 4A), lower peak heart rate, lower workload, and steeper $\mathrm{VE} / \mathrm{VCO}_{2}$ slope (Table 2). Patients

2 classified as 'high probability' had a higher logistic H2FPEF score compared to patients with

3 intermediate or low probability, indicating high likelihood of elevated exPAWP (Figure 4B,

4 Table 2). Patients in the 'high probability' group were older, more frequently had atrial fibrillation,

5 and had worse renal function compared to patients with intermediate or low probability (Table 2).

6 Finally, compared to the other groups, patients classified as 'high probability' had higher resting

$7 \quad E / e^{\prime}$, higher exE/e' and exercise sPAP, and reduced peak cardiac index (Table 2).

8

9 Figure 5 shows the percentage of true and false positive tests using different DST criteria for

10 diagnosis of HFpEF. All current criteria show a lack of sensitivity: of patients with invasively

11 proven HFpEF, ASE/EACVI recommendations detected $43 \%$ 9,10, the Heart Failure Association

12 consensus on HFpEF $21 \%$ 7, and $e x E / \mathrm{e}^{\prime}$ alone $50 \%$. Our decision tree detected $100 \%$ of HFpEF

13 patients, at the cost of $13 \%$ false positives (compared to $0 \%$ for all recommendations).

\section{Reproducibility of peak exercise $\mathbf{S}^{\prime}$}

$15 E x S^{\prime}$ 'was measured successfully in all patients in the exRHC cohort, and in 362 patients (96\%) in

16 the DST cohort. ExS' measured by color TDI was highly reproducible, with an interobserver

17 agreement of 0.97 (CI 0.92-0.99). Measurement of mPAP/CO showed good interobserver

18 agreement of 0.73 (CI 0.53-0.87). Bland-Altman plots are provided in Supplemental Figure 4. 
medRxiv preprint doi: https://doi.org/10.1101/2020.12.16.20248175; this version posted December 18, 2020. The copyright holder for this preprint (which was not certified by peer review) is the author/funder, who has granted medRxiv a license to display the preprint in perpetuity. All rights reserved. No reuse allowed without permission.

\section{Discussion}

2 In this study, we established septal $e x S^{\prime}$ as a compelling parameter to improve identification of

3 elevated cardiac filling pressures in a small cohort of patients referred for simultaneous exRHC and

4 DST. A threshold of $e x S^{\prime}<9.5 \mathrm{~cm} / \mathrm{s}$ had a high sensitivity and specificity to identify

5 exPAPW $\geq 25 \mathrm{mmHg}$. We propose a decision tree to diagnose HFpEF on DST, incorporating exS'

6 and mPAP/CO slope. Applying this decision tree to 376 patients with suspected HFpEF

7 substantially improved the diagnostic yield of DST from 20\% (using guideline recommendations)

8 to $71 \%$ (using the decision tree).

9

Current ASE/EACVI recommendations recommend the use of $e x E / e$ ' and sPAP to diagnose HFpEF on $\operatorname{DST}^{9,10}$. These recommendations are based on early studies focusing solely on exE/e', disregarding other possible correlates of elevated exPAWP ${ }^{18}$. Most of these were performed without concurrent exPAWP measurement, and subsequent invasive validation studies showed at most a moderate correlation between $e x E / e^{\text {' and PAPW }}{ }^{11,19}$. Another limitation of the evaluation of $e x E / e^{\prime}$ relates to the influences of increased respiratory rate and tachycardia that occur during exercise. Hence, fusion of E/A waves and e'/a' waves often occurs beyond heart rates of $100 \mathrm{bpm}$, thereby compromising the accuracy of this assessment. $E x E / e$ ' has a good specificity for diagnosis of elevated exPAWP, but shows poor sensitivity ${ }^{11,18}$. This leaves many DST with an inconclusive result, up to $80 \%$ in our population.

A recent Heart Failure Association expert consensus paper proposed DST in patients with an intermediate to high pre-test probability of HFpEF 7. However, the authors suggested a stricter cutoff of $>3.4 \mathrm{~m} / \mathrm{s}$ for exercise TR, which further reduces sensitivity, as confirmed by our study findings.

It is well accepted that patients with HFpEF not only have impaired diastolic cardiac function, but also suffer from subtle reductions in systolic function despite a normal LVEF ${ }^{20}$. Measurements of longitudinal function, such as strain and strain rate, have emerged as less afterload dependent surrogates of systolic function, but are affected by respiratory variation in image quality at peak 
medRxiv preprint doi: https://doi.org/10.1101/2020.12.16.20248175; this version posted December 18, 2020. The copyright holder for this

1 exercise. In contrast, systolic velocity of the mitral annulus $\left(S^{\prime}\right)$ can be easily obtained at peak exercise regardless of heart rate and image quality (in 96\% of patients in our study), while showing high reproducibility. From a mechanistic point of view, the reduction of $e x S^{\prime}$ in patients with increased exPAWP during exercise may be explained by decreased diastolic suction and elastic recoil resulting from a lack of systolic functional reserve. Hence, as the capacity of the LV to decrease its end-systolic volume during exercise is reduced, the driving force for early diastolic suction to enable is impaired and rapid LV filling becomes exquisitely dependent on increased filling pressures across the mitral valve.

Other studies have previously evaluated longitudinal LV function during exercise in HFpEF patients. Wang et al. found reduced values of resting $S^{\prime}$ and $e x S^{\prime}$ in HFpEF patients compared to controls ${ }^{21,22}$. ExS' correlated well with peak $\mathrm{VO}_{2}{ }^{23,24}$, and was a significant predictor of all-cause mortality and HF hospitalization ${ }^{25}$. Also, right ventricular $S^{\prime}$ was demonstrated to be a useful marker of longitudinal function during exercise, and was able to identify athletes at risk of arrythmias ${ }^{26}$.

Using our proposed decision tree (Figure 3B), 64\% of patients with inconclusive DST could be reclassified as high or low probability of HFpEF, substantially improving the diagnostic yield of DST. In the decision tree, we maintain $e x E / e$ ' in the first step because of its extensive validation in multiple populations, and its high specificity ${ }^{11,18,27}$. Note that we use a threshold of $\geq 15$ because we routinely record only septal $e^{\prime}$, when using average $E / e^{\prime}$ a threshold of $\geq 14$ is more appropriate ${ }^{9}$. In a next step, exS' is evaluated and HFpEF is confirmed for a value $<9.5 \mathrm{~cm} / \mathrm{s}$ based on our current findings. As the group of patients with low exS' remains large, we decided to add evidence of exercise pulmonary hypertension as a third step. In our opinion, an indication of exercise pulmonary hypertension must be present for the diagnosis of HFpEF using DST alone, because of the close pathophysiological relation between left atrial pressure, PAWP and MPAP. We chose mPAP/CO slope rather than sPAP, because (1) mPAP/CO slope is more accurate in situations where peak exercise $\mathrm{CO}$ is abnormal, such as in $\mathrm{HFpEF}{ }^{14}$, (2) $\mathrm{mPAP} / \mathrm{CO}$ was the next-to-best 
medRxiv preprint doi: https://doi.org/10.1101/2020.12.16.20248175; this version posted December 18, 2020. The copyright holder for this

1 parameter in the AUC analysis, and (3) in the exRHC cohort all patients with exS $^{\prime}<9.5 \mathrm{~cm} / \mathrm{s}$ and

4 In a number of patients, exercise pulmonary hypertension was not present, but $e x S^{\prime}<9.5 \mathrm{~cm} / \mathrm{s}$

5 indicated elevated exPAWP. This may reflect early HFpEF in patients with relatively compliant left

6 atrium and pulmonary vasculature, underestimation of mPAP/CO slope on DST, or lower specificity of exS' in an unselected population. In these cases, other methods can aid to establish a final diagnosis of HFpEF. The gold standard investigation for these patients remains an exRHC, as sPAP and mPAP/CO slope are generally underestimated on echocardiography when compared to invasive measurement ${ }^{14}$.

Our study results should be interpreted in the context of some limitations. Color TDI is angledependent, however the use of offline repositioning and the use of septal rather than lateral $S$, mitigated the impact of this limitation. Whether using a pulse wave TDI signal optimized for assessing $S^{\prime}$ has equal diagnostic capabilities, remains to be studied.

A 'gold standard' to diagnose HFpEF non-invasively is currently still lacking. As such, we used several surrogate measures (peak $\mathrm{VO}_{2}$, logistic $\mathrm{H} 2 \mathrm{FPEF}$ score) and supporting features (diastolic function, typical clinical characteristics) in the DST cohort to demonstrate differences between patients classified as high, intermediate or low probability of HFpEF.

Furthermore, the small sample size of the exRHC cohort compared to the DST cohort suggests a highly selected population. Our results should be validated in a larger patient cohort.

We conclude that exS' was the most accurate parameter to identify patients with elevated cardiac filling pressures in a cohort of patients referred for exRHC because of exertional dyspnea. We propose a decision tree to diagnose elevated exPAWP on DST in patients with exertional dyspnea and LVEF $\geq 50 \%$. Applying this decision tree for the diagnosis of HFpEF on DST substantially improved the diagnostic yield from $20 \%$ (using guideline recommendations alone) to $71 \%$ (using the decision tree). Validation in a separate exRHC cohort is desirable before application of our findings in clinical practice. 
medRxiv preprint doi: https://doi.org/10.1101/2020.12.16.20248175; this version posted December 18, 2020. The copyright holder for this preprint (which was not certified by peer review) is the author/funder, who has granted medRxiv a license to display the preprint in perpetuity. All rights reserved. No reuse allowed without permission.

1 
medRxiv preprint doi: https://doi.org/10.1101/2020.12.16.20248175; this version posted December 18, 2020. The copyright holder for this preprint (which was not certified by peer review) is the author/funder, who has granted medRxiv a license to display the preprint in perpetuity. All rights reserved. No reuse allowed without permission.

\section{Acknowledgements}

2 We thank the sonographers, nurses and cardiology fellows at the Department of Cardiology, Jessa

3 Hospital, Hasselt for their invaluable assistance during the exRHC and DST procedures.

4

\section{Funding}

$6 \quad$ F.H.V. is supported by the Special Research Fund (BOF) of Hasselt University (BOF19PDo4).

7 G.C. is supported by the Frans Van De Werf Fund for Clinical Cardiovascular Research and the 8 Mathilde Horlait-Dapsens Scholarship.

9

10 
medRxiv preprint doi: https://doi.org/10.1101/2020.12.16.20248175; this version posted December 18, 2020. The copyright holder for this

\section{References}

2 1. Dunlay SM, Roger VL, Redfield MM. Epidemiology of heart failure with preserved ejection 3 fraction. Nat Rev Cardiol 2017; 14: 591-602.

42 Van Riet EES, Hoes AW, Limburg A, et al. Prevalence of unrecognized heart failure in older $5 \quad$ persons with shortness of breath on exertion. Eur J Heart Fail 2014; 16: 772-777.

6 3. Ponikowski P, Voors AA, Anker SD, et al. 2016 ESC Guidelines for the diagnosis and treatment of acute and chronic heart failure. Eur Heart $J$ 2016; 37: 2129-2200.

4. Yancy CW, Jessup M, Bozkurt B, et al. 2017 ACC/AHA/HFSA Focused Update of the 2013 ACCF/AHA Guideline for the Management of Heart Failure. $J$ Am Coll Cardiol 2017; 70: $776-803$.

5. Borlaug BA, Nishimura RA, Sorajja P, et al. Exercise hemodynamics enhance diagnosis of early heart failure with preserved ejection fraction. Circ Heart Fail 2010; 3: 588-595.

6. Berry NC, Manyoo A, Oldham WM, et al. Protocol for Exercise Hemodynamic Assessment:

7. Pieske B, Tschöpe C, de Boer RA, et al. How to diagnose heart failure with preserved ejection Failure Association (HFA) of the European Society of Cardiology (ESC). Eur Heart $J$ 2019; 40: $3297-3317$.

8. Borlaug BA, Kane GC, Melenovsky V, et al. Abnormal right ventricular-pulmonary artery coupling with exercise in heart failure with preserved ejection fraction. Eur Heart $J$ 2016; 37: 3293.2-3302.

9. Lancellotti P, Pellikka PA, Budts W, et al. The Clinical Use of Stress Echocardiography in Non-Ischaemic Heart Disease: Recommendations from the European Association of Cardiovascular Imaging and the American Society of Echocardiography. $J A m$ Soc Echocardiogr 2017; 30: 101-138.

10. Nagueh SF, Smiseth OA, Appleton CP, et al. Recommendations for the Evaluation of Left Ventricular Diastolic Function by Echocardiography: An Update from the American Society of Echocardiography and the European Association of Cardiovascular Imaging. $J$ Am Soc 
medRxiv preprint doi: https://doi.org/10.1101/2020.12.16.20248175; this version posted December 18, 2020. The copyright holder for this preprint (which was not certified by peer review) is the author/funder, who has granted medRxiv a license to display the preprint in perpetuity. All rights reserved. No reuse allowed without permission.

Echocardiogr 2016; 29: 277-314.

11. Obokata M, Kane GC, Reddy YNV, et al. Role of Diastolic Stress Testing in the Evaluation for Heart Failure With Preserved Ejection Fraction. Circulation 2017; 135: 825-838.

12. Guazzi M, Arena R, Halle M, et al. 2016 focused update: clinical recommendations for cardiopulmonary exercise testing data assessment in specific patient populations. Eur Heart $J$ 2018; 39: 1144-1161.

13. Lang RM, Badano LP, Mor-Avi V, et al. Recommendations for Cardiac Chamber Quantification by Echocardiography in Adults: An Update from the American Society of Echocardiography and the European Association of Cardiovascular Imaging. $J$ Am Soc Echocardiogr 2015; 28: 1-39.e14.

14. Claessen G, La Gerche A, Voigt J-U, et al. Accuracy of Echocardiography to Evaluate Pulmonary Vascular and RV Function During Exercise. J Am Coll Cardiol Img 2016; 9: $532-543$

15. Wolsk E, Bakkestrøm R, Thomsen JH, et al. The Influence of Age on Hemodynamic Parameters During Rest and Exercise in Healthy Individuals. J Am Coll Cardiol Heart Fail 2017; 5: 337-346.

16. Reddy YNV, Carter RE, Obokata M, et al. A Simple, Evidence-Based Approach to Help Guide Diagnosis of Heart Failure With Preserved Ejection Fraction. Circulation 2018; 138: 861870 .

17. Gorter TM, Obokata M, Reddy YN V, et al. Exercise unmasks distinct pathophysiologic features in heart failure with preserved ejection fraction and pulmonary vascular disease. Eur Heart J 2018; 39: 2825-2835.

18. Ha J-W, Andersen OS, Smiseth OA. Diastolic Stress Test. J Am Coll Cardiol Img 2020; 13: $272-282$.

19. Burgess MI, Jenkins C, Sharman JE, et al. Diastolic Stress Echocardiography: Hemodynamic Validation and Clinical Significance of Estimation of Ventricular Filling Pressure With Exercise. J Am Coll Cardiol 2006; 47: 1891-1900.

20. Gevaert AB, Boen JRA, Segers VF, et al. Heart Failure With Preserved Ejection Fraction: A Review of Cardiac and Noncardiac Pathophysiology. Front Physiol 2019; 10: 638, 1-14. 
medRxiv preprint doi: https://doi.org/10.1101/2020.12.16.20248175; this version posted December 18, 2020. The copyright holder for this

1 21. Wang J, Fang F, Wai-Kwok Yip G, et al. Changes of ventricular and peripheral performance in patients with heart failure and normal ejection fraction: Insights from ergometry stress

22. Wang J, Fang F, Yip GWK, et al. Quantification of left ventricular performance in different heart failure phenotypes by comprehensive ergometry stress echocardiography. Int $J$ Cardiol 2013; 169: 311-315.

23. Wang J, Fang F, Yip GW-K, et al. Importance of chronotropic response and left ventricular long-axis function for exercise performance in patients with heart failure and preserved ejection fraction. Int $J$ Cardiol 2016; 202: 339-343.

24. Masada K, Hidaka T, Harada Y, et al. Mitral systolic velocity at peak exercise predicts impaired exercise capacity in patients with heart failure with preserved ejection fraction. Echocardiography 2017; 34: 217-225.

25. Wang J, Fang F, Wai-Kwok Yip G, et al. Left ventricular long-axis performance during exercise is an important prognosticator in patients with heart failure and preserved ejection fraction. Int $J$ Cardiol 2015; 178: 131-135.

26. Claeys M, Claessen G, Claus $P$, et al. Right ventricular strain rate during exercise accurately identifies male athletes with right ventricular arrhythmias. Eur Heart $J$ Cardiovasc Img 2019; ePub ahead of print, DOI: 10.1093/ehjci/jez228.

27. Ha JW, Oh JK, Pellikka PA, et al. Diastolic stress echocardiography: A novel noninvasive diagnostic test for diastolic dysfunction using supine bicycle exercise Doppler echocardiography. J Am Soc Echocardiogr 2005; 18: 63-68. 


\section{$1 \quad$ Figure legends}

2 Figure 1: DST parameters associated with elevated exPAWP. Results of non-invasive E/e'

3 (A), S' (B), systolic PAP (C), cardiac index (D), and mean PAP/CO slope (E) in the exRHC cohort at 4 rest and peak exercise. Red: patients with elevated exPAWP ( $n=14)$, green: patients with normal 5 exPAWP ( $\mathrm{n}=8)$. P values from linear mixed models. ${ }^{*} \mathrm{p}<.05$ in multiplicity-adjusted comparison of 6 peak values. $\mathrm{CO}=$ cardiac output, exPAWP $=$ pulmonary artery wedge pressure during peak 7 exercise, $\mathrm{mPAP}=$ mean pulmonary artery pressure, $\mathrm{PAP}=$ pulmonary artery pressure.

Figure 2: Receiver operating characteristic curves. Receiver operating characteristic curves for identifying elevated exPAWP using exS'(red), mPAP/CO slope (green), peak CI (brown), exE/e' (blue) and peak sPAP (grey). AUC = area under the receiver operating characteristic curve, $\mathrm{CI}=$ cardiac index, $\mathrm{CO}=$ cardiac output, exE/e' = highest $\mathrm{E} / \mathrm{e}^{\prime}$ recorded during exercise, $\mathrm{exS} \mathrm{S}^{\prime}=\mathrm{S}^{\prime}$ at peak exercise, $\mathrm{mPAP}=$ mean pulmonary artery pressure, $\mathrm{sPAP}=$ systolic pulmonary artery pressure.

Figure 3: Proposed decision tree for diagnosis of HFpEF on DST. A: Derivation of the decision tree in the exRHC cohort. Step 1: the existing approach in ASE/EAVCI recommendations is maintained. Step 2: exS' is determined and HFpEF is confirmed if $<9.5 \mathrm{~cm} / \mathrm{s}$. Thus all patients with exPAPW $\geq 25 \mathrm{mmHg}$ are identified. A single patient is false positive using this approach. Adding mPAP/CO does not provide additional information in the exRHC cohort. B: Application of the decision tree to the non-invasive DST cohort. Of patients with a positive DST according to ASE/EACVI recommendations, $98 \%$ had $e x S$ ' $<9.5 \mathrm{~cm} / \mathrm{s}$. None of the patients with 'normal' DST according to ASE/EACVI recommendations had $e x S^{\prime}<9.5 \mathrm{~cm} / \mathrm{s}$. Of 302 patients with inconclusive results according to ASE/EACVI recommendations, 104 (34\%) had $\operatorname{exS}>9.5 \mathrm{~cm} / \mathrm{s}$, we propose that probability of HFpEF is low in these patients. A total of 184 patients (61\% of inconclusive results) had $e x S^{\prime}<9.5 \mathrm{~cm} / \mathrm{s}$. Of these, 88 had elevated mPAP/CO slope suggesting exercise pulmonary hypertension, we propose that probability of HFpEF is high in these patients. In the 96 patients with normal mPAP/CO slope, we propose to perform additional investigations before establishing a diagnosis of HFpEF. 
medRxiv preprint doi: https://doi.org/10.1101/2020.12.16.20248175; this version posted December 18, 2020. The copyright holder for this preprint (which was not certified by peer review) is the author/funder, who has granted medRxiv a license to display the preprint in perpetuity.

2 Figure 4: Performance of decision tree in the DST cohort. To evaluate the performance of 3 the decision tree (Figure $3 \mathrm{~B}$ ), the probability of $\mathrm{HFpEF}$ according to the decision tree

4 (high/intermediate/low) was compared to surrogate $\mathrm{HFpEF}$ indicators. A: Peak $\mathrm{VO}_{2}$ significantly

5 differs between patients with high, intermediate and low probability of HFpEF according to the

6 decision tree B: Logistic H2FPEF score, which calculates the probability of elevated exPAWP in

7 percentage through clinical and echocardiographic parameters ${ }^{16}$, significantly differed between

8 patients at high and intermediate or low probability of HFpEF according to the decision tree.

9 Multiplicity-corrected $P$ values from Kruskal-Wallis test. HFpEF = heart failure with preserved 10 ejection fraction, Peak $\mathrm{VO}_{2}=$ peak oxygen uptake.

Figure 5: Performance of different DST algorithms for detecting elevated exPAWP.

13 True positives: correct diagnosis of HFpEF in patients with elevated exPAWP. False positives:

14 wrong diagnosis of HFpEF in patients with normal exPAWP. Our proposed decision tree (Figure 3) recommendations propose to diagnose $\mathrm{HFpEF}$ if $e x E / e^{\prime}$ is $\geq 15$, baseline $e^{\prime}$ is $<7 \mathrm{~cm} / \mathrm{s}$, and exercise TR is $>2.8 \mathrm{~m} / \mathrm{s}^{9,10}$. The Heart Failure Association consensus (HFA-PEFF score) proposes stricter thresholds: exercise TR $>3.4 \mathrm{~m} / \mathrm{s}$ and average (not septal) $e x E / e^{\prime} \geq 15^{7}$. ExE/e' alone considers $e x E / e^{\prime} \geq 15$. These approaches all detect $\leq 50 \%$ of true positives. 


\section{Tables}

2 Table 1: Baseline characteristics of the study populations

\begin{tabular}{|c|c|c|c|}
\hline Characteristic & $\begin{array}{l}\text { ExRHC cohort } \\
(n=22)\end{array}$ & $\begin{array}{l}\text { DST cohort } \\
(n=376)\end{array}$ & $\begin{array}{c}\mathbf{P} \\
\text { value }\end{array}$ \\
\hline Age, years & $65(57-71)$ & $68(60-74)$ & .138 \\
\hline Female sex & $10(45)$ & $221(59)$ & .313 \\
\hline Heart rate, bpm & $68(62-72)$ & $70(63-82)$ & .435 \\
\hline Systolic blood pressure, $\mathrm{mmHg}$ & $150(127-155)$ & $140(124-154)$ & .442 \\
\hline $\mathrm{BMI}, \mathrm{kg} / \mathrm{m}^{2}$ & $27.5(26.1-30.9)$ & $27.8(24.7-31.2)$ & .929 \\
\hline \multicolumn{4}{|l|}{ Past medical history } \\
\hline Atrial fibrillation & $5(23)$ & $78(21)$ & .999 \\
\hline Coronary heart disease & $8(36)$ & $57(15)$ & .022 \\
\hline Diabetes & $3(14)$ & $51(14)$ & .999 \\
\hline Hypertension & $11(50)$ & $212(56)$ & .684 \\
\hline Valvular heart disease & $1(5)$ & $9(2)$ & .999 \\
\hline \multicolumn{4}{|l|}{ Medication use } \\
\hline ACE inhibitor or ARB & $6(27)$ & $93(25)$ & .999 \\
\hline Aldosterone antagonist & $4(18)$ & $40(11)$ & .483 \\
\hline Beta blocker & $11(50)$ & $108(29)$ & .064 \\
\hline Calcium antagonist & $4(18)$ & $41(11)$ & .536 \\
\hline Diuretic & $5(23)$ & $74(20)$ & .999 \\
\hline Nitrate & $2(9)$ & $12(3)$ & .416 \\
\hline \multicolumn{4}{|l|}{ Laboratory analysis } \\
\hline Hemoglobin, g/dL & $13.8(12.7-15.0)$ & $\begin{array}{l}13.8(12.8-14.7) \\
(n=243)\end{array}$ & .577 \\
\hline EGFR, mg/dL & $\begin{array}{c}72(67-80) \\
(n=16)\end{array}$ & $\begin{array}{c}73(58-86) \\
(n=218)\end{array}$ & .481 \\
\hline
\end{tabular}

3 Continuous variables: median (IQR), P value from Mann-Whitney-U test. Categorical variables: no.

4 (\%), $\mathrm{P}$ value from Chi-square test. $\mathrm{ACE}=$ angiotensin conversion enzyme, $\mathrm{ARB}=$ angiotensin

$5 \quad$ receptor blocker, $\mathrm{BMI}=$ Body mass index, EGFR $=$ Estimated glomerular filtration rate using CKD-

6 EPI formula. 
1 Table 2: Selected characteristics and measurements in patients with inconclusive

2 DST, stratified according HFpEF probability (decision tree).

\begin{tabular}{|c|c|c|c|c|}
\hline Surrogate HFpEF indicators & $\begin{array}{c}\text { High } \\
\text { probability } \\
(n=88)\end{array}$ & $\begin{array}{l}\text { Intermediate } \\
\text { probability } \\
(n=96)\end{array}$ & $\begin{array}{l}\text { Low probability } \\
(n=104)\end{array}$ & $\begin{array}{c}\mathbf{P} \\
\text { value }\end{array}$ \\
\hline H2FPEF score, \% & $55(44-75) *$ & $42(23-54)$ & $32(19-49)$ & $<.001$ \\
\hline Peak VO ${ }_{2}, \mathrm{~mL} / \mathrm{kg} / \mathrm{min}$ & $12.9(10.6-16.0) * \dagger$ & $15 \cdot 3(12.0-18.6) *$ & $18.8(15.8-23.4)$ & $<.001$ \\
\hline \multicolumn{5}{|l|}{ Clinical characteristic } \\
\hline Age, years & $72(67-78) *+$ & $65(59-70) *$ & $61(53-68)$ & $<.001$ \\
\hline Women & $60(68) *$ & $68(71) *$ & $35(34)$ & $<.001$ \\
\hline Heart rate, bpm & $67(61-76) *$ & $70(65-80)$ & $71(65-86)$ & .009 \\
\hline Systolic blood pressure, $\mathrm{mmHg}$ & $144(124-155)$ & $138(123-149)$ & $134(123-148)$ & .196 \\
\hline BMI, $\mathrm{kg} / \mathrm{m}^{2}$ & $28.6(25.5-30.9)$ & $28.2(24.7-31.7)$ & $27.3(24.4-31.3)$ & .541 \\
\hline \multicolumn{5}{|l|}{ Past medical history } \\
\hline Atrial fibrillation & $28(32) * \dagger$ & $8(1)$ & $14(13)$ & $<.001$ \\
\hline Coronary heart disease & $11(12)$ & $9(9)$ & $21(20)$ & .077 \\
\hline Diabetes & $14(16)$ & $11(11)$ & $11(11)$ & .531 \\
\hline Hypertension & $55(62)$ & $53(55)$ & $46(44)$ & .043 \\
\hline Valvular heart disease & $\mathrm{o}(\mathrm{O})$ & $1(<1)$ & $2(<1)$ & .422 \\
\hline \multicolumn{5}{|l|}{ Laboratory analysis } \\
\hline Hemoglobin, g/dL & $\begin{array}{l}13.7 \quad(12.8-14.5) \\
(n=58)\end{array}$ & $\begin{array}{l}13.8(13.1-14.6) \\
(n=60)\end{array}$ & $\begin{array}{l}14.2(12.9-15.1) \\
(n=65)\end{array}$ & .432 \\
\hline EGFR, mg/dL & $\begin{array}{l}66(56-78) * \dagger \\
(n=51)\end{array}$ & $\begin{array}{c}82(65-91) \\
(n=57)\end{array}$ & $\begin{array}{c}80(71-97) \\
(n=55)\end{array}$ & $<.001$ \\
\hline \multicolumn{5}{|l|}{ Echocardiography: rest } \\
\hline$E / e$, ratio & $11.7(9.8-13.5) *$ & $10.4(8.6-12.2) *$ & $9.0(7.6-11.0)$ & $<.001$ \\
\hline$S$, ratio & $4.0(3.0-5.0) *$ & $4.0(3.0-5.0) *$ & $6.0(5.0-8.0)$ & $<.001$ \\
\hline Systolic PAP, mmHg & $22(19-25)$ & $22(20-25)$ & $21(18-25)$ & .948 \\
\hline LV ejection fraction, \% & $62(56-67)$ & $62(55-70)$ & $63(56-68)$ & .861 \\
\hline Cardiac index, $\mathrm{L} / \mathrm{m}^{2}$ & $2.3(1.9-2.9) *$ & $2.5(2.1-2.9)$ & $2.5(2.2-3.0)$ & .022 \\
\hline $\mathrm{LV}$ mass index, $\mathrm{g} / \mathrm{m}^{2}$ & $81(70-99)$ & $79(66-92)$ & $83(64-103)$ & .439 \\
\hline Left atrial volume index, $\mathrm{mL} / \mathrm{m}^{2}$ & $24(19-31) *$ & $20(16-29)$ & $19(15-24)$ & .001 \\
\hline \multicolumn{5}{|c|}{ Echocardiography: peak exercise } \\
\hline$E / e^{\prime}$, ratio ${ }^{*}$ & $12.6(10.4-14.4) * \dagger$ & $11.0(9.3-12.8) *$ & $9.9(8.4-11.0)$ & $<.001$ \\
\hline
\end{tabular}


medRxiv preprint doi: https://doi.org/10.1101/2020.12.16.20248175; this version posted December 18, 2020. The copyright holder for this preprint (which was not certified by peer review) is the author/funder, who has granted medRxiv a license to display the preprint in perpetuity. All rights reserved. No reuse allowed without permission.

\begin{tabular}{|l|l|l|l|l|}
\hline$S$ & $7.0(5.4-8.0)^{*}$ & $7.0(6.0-8.6)^{*}$ & $10.7(10.0-13.0)$ & $<.001$ \\
\hline Systolic PAP, mmHg & $52(45-59)^{* *}$ & $44(38-49)$ & $45(41-52)$ & $<.001$ \\
\hline LV ejection fraction, \% & $66(60-75)$ & $71(64-78)$ & $70(64-76)$ & .061 \\
\hline Cardiac index, L/min/m² & $4.4(3.7-5.2)^{*}+$ & $5.4(4.9-6.3)^{*}$ & $6.3(5.1-6.8)$ & $<.001$ \\
\hline Mean PAP/CO slope, $\mathrm{mmHg} / \mathrm{L} / \mathrm{min}$ & $4.5(3.7-5.7)^{*}+$ & $2.4(1.9-2.8)$ & $2.1(1.5-2.7)$ & $<.001$ \\
\hline
\end{tabular}

Cardiopulmonary exercise test

\begin{tabular}{|l|l|l|l|l|}
\hline Peak heart rate, bpm & $111(97-125)^{* \dagger}$ & $121(110-137) *$ & $135(118-149)$ & $<.001$ \\
\hline Workload, W & $69(52-88)^{*}+$ & $82(65-108) *$ & $118(91-152)$ & $<.001$ \\
\hline $\mathrm{VE} / \mathrm{VCO}_{2}$ slope, unitless & $31.8(28.3-36.9)^{* \dagger}$ & $29.5(26.3-33.4)^{*}$ & $26.8(24.8-29.7)$ & $<.001$ \\
\hline $\mathrm{CO} / \mathrm{VO}_{2}$ slope, unitless & $5.1(3.9-6.1) \dagger$ & $6.6(5.1-8.0)^{*}$ & $5 \cdot 3(4.4-6.7)$ & $<.001$ \\
\hline
\end{tabular}

1 See Figure 3B for decision tree. Continuous variables: median (IQR), P value from Kruskall-Wallis

2 test. Categorical variables: no. (\%), $\mathrm{P}$ value from Chi-square test. BMI = Body mass index,

$3 \mathrm{CO}=$ cardiac output, EGFR = Estimated glomerular filtration rate using CKD-EPI formula,

4 H2FPEF score = score estimating likelihood of heart failure with preserved ejection fraction based

5 on ${ }^{16}, \mathrm{LV}=$ left ventricular, $\mathrm{PAP}=$ pulmonary artery pressure, PAWP = pulmonary artery wedge

6 pressure, $\mathrm{VE}=$ ventilation, $\mathrm{VCO}_{2}=$ carbon dioxide removal, $\mathrm{VO}_{2}=$ oxygen uptake, ${ }^{*} \mathrm{p}<0.05 \mathrm{vs}$. Low

7 probability, ${ }^{\dagger} \mathrm{p}<0.05$ vs. Intermediate probability, ${ }^{*}$ Highest $E / e$ ' value obtained during entire

8 duration of exercise. 
A
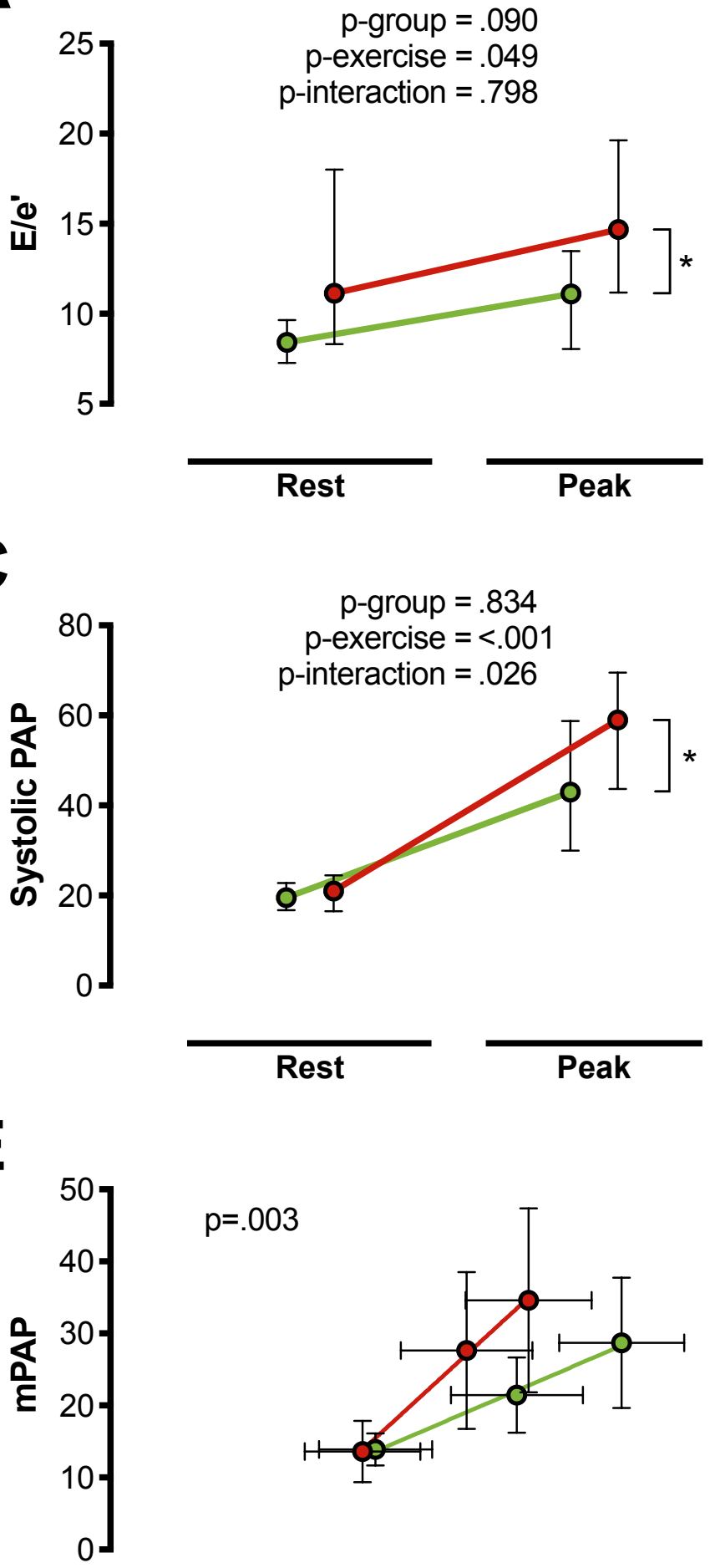

p-group $=.025$

p-exercise $=.002$

$p$-interaction $=.002$

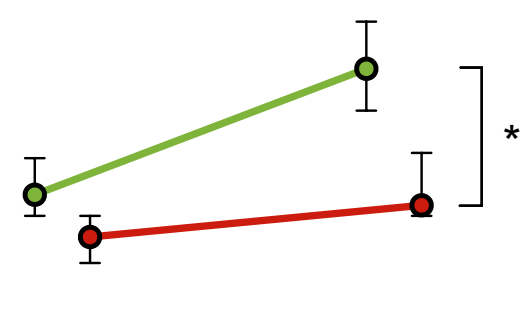

Rest

Peak

D

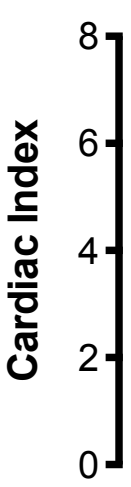

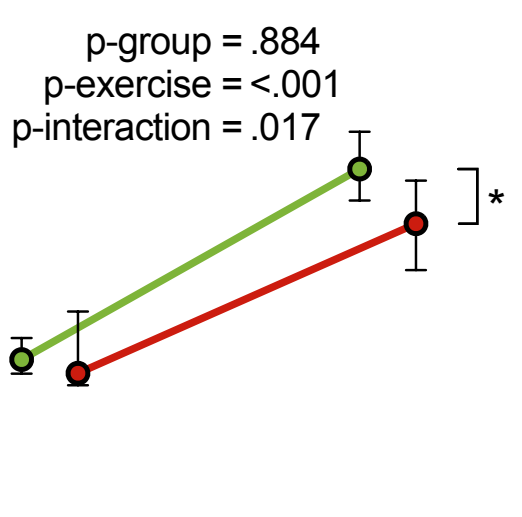

Rest

Peak

-

-

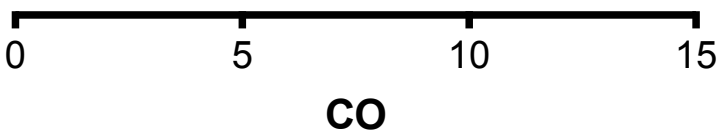




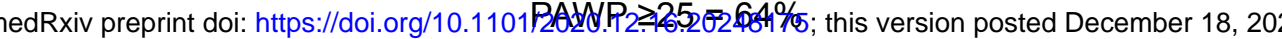
oreprint (which was not certified by peer review) is the author/funder, who has granted medRxiv a license to

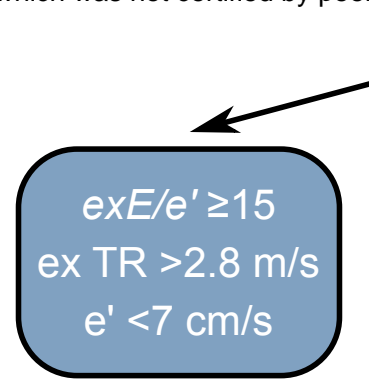

$\mathrm{n}=6$

PAWP $\geq 25=100 \%$ All rights reserved. No reuse allowed without permission.

\section{Dyspnea \\ LVEF $\geq 50 \%$}

$$
\mathrm{n}=22
$$

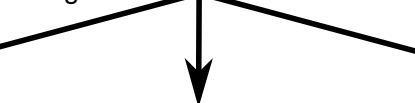

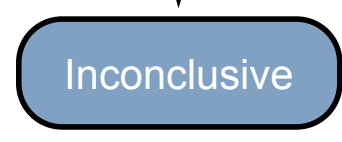

$\mathrm{n}=15$

PAWP $\geq 25=47 \%$

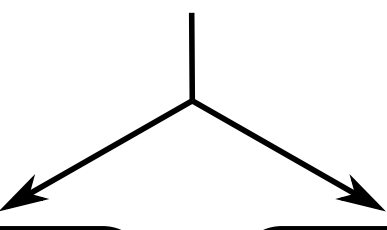

\section{exS $<9.5$}

$\mathrm{n}=9$

PAWP $\geq 25=89 \%$

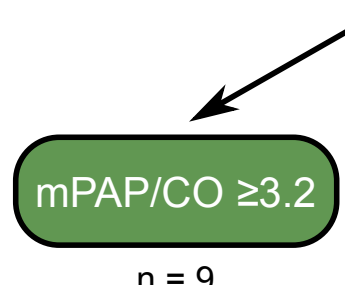

$\mathrm{n}=9$

PAWP $\geq 25=89 \%$

\section{$\operatorname{ex} S^{\prime}>9.5$}

$$
\mathrm{n}=6
$$

PAWP $\geq 25=0 \%$
exE/e' $<10$

ex TR $<2.8 \mathrm{~m} / \mathrm{s}$

$$
\mathrm{n}=1
$$

PAWP $\geq 25=0 \%$

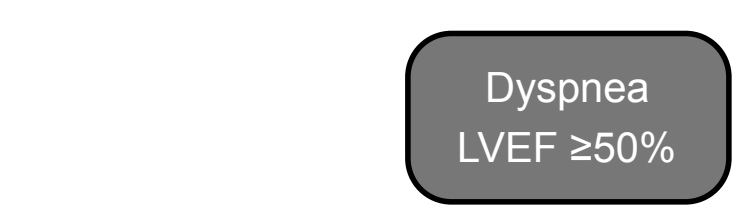

$n=376$

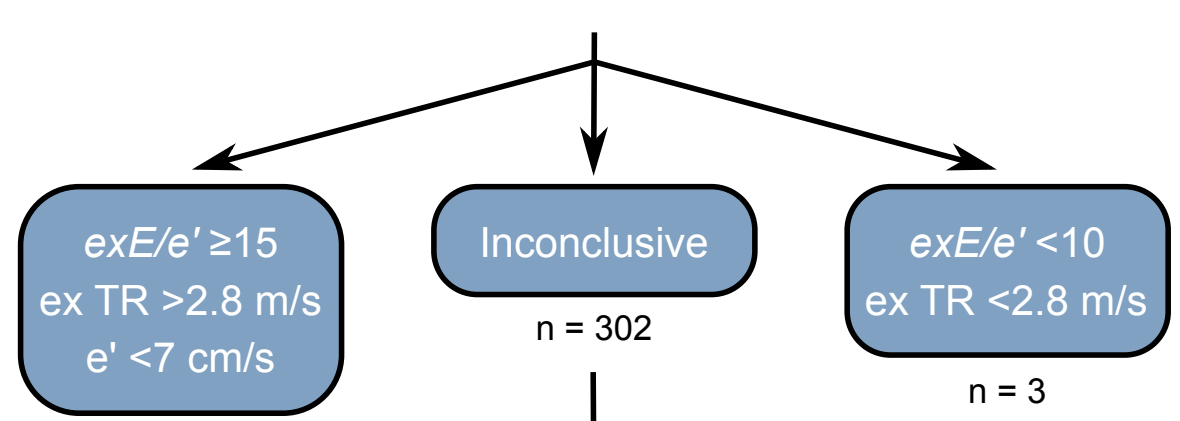

$n=71$

Low probability

High probability

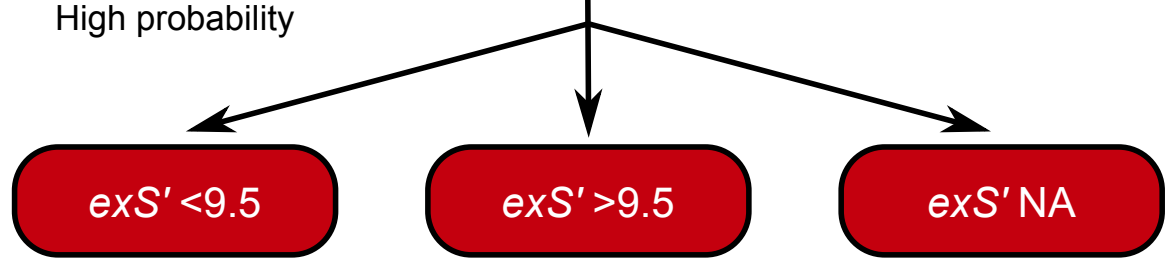

$$
\mathrm{n}=184
$$$$
n=104
$$$$
n=14
$$

Low probability

Indeterminate (exRHC)

\section{$\mathrm{mPAP} / \mathrm{CO} \geq 3.2$}

$n=88$

High probability

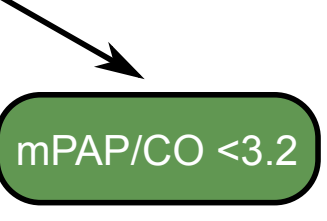

$$
\mathrm{n}=96
$$

Intermediate probability Confirm with exRHC 


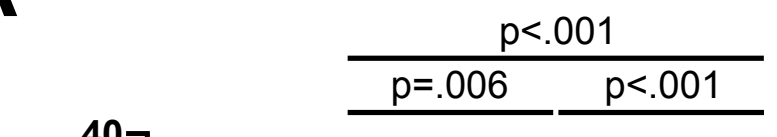

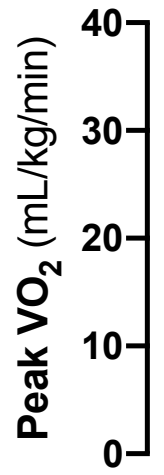
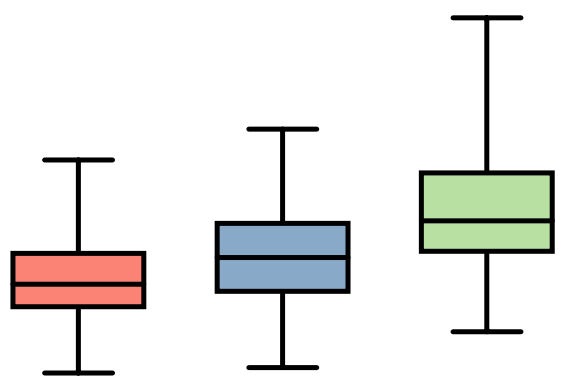

High Intermediate Low HFpEF probability (decision tree)

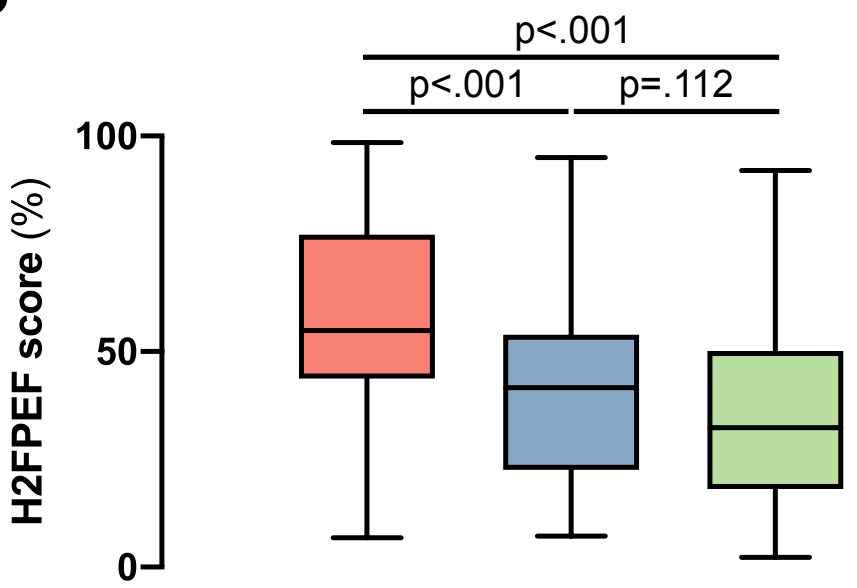

High Intermediate Low HFpEF probability (decision tree) 


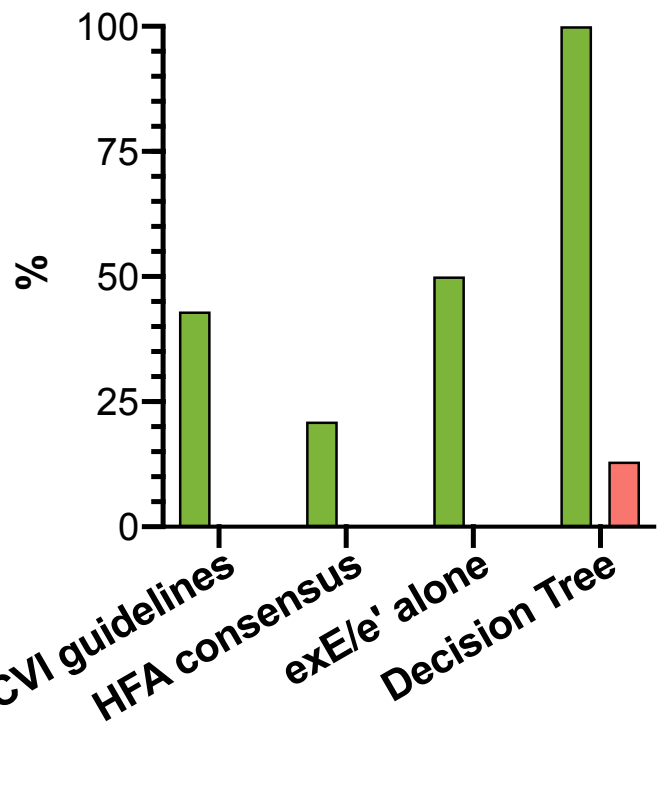

True positives

$\square$ False positives 